\section{The end is not nigh}

Roger Jones'1 gloomy prognostications about general practice and the health service show that fashion is cyclic. Sixteen years ago Duncan Keeley, writing in the $B M J$, was equally anxious about the future of general practice and even predicted Professor Darzi's polyclinics. ${ }^{2}$ In the meantime general practice has flourished. Each contractual shift has induced a temporary dip in job satisfaction and a sustained increase in income, making British GPs the highest paid family doctors in Europe. A revolving door effect has meant that for every task acquired (like chronic disease management) another has been shed (like out-of-hours responsibilities) making work more intense but shorter in duration. GPs may grumble about being industrialised but they mostly accommodate to change and assimilate it, and get on with the job.

It is always tempting to portray GPs as doughty fighters for personalised and continuing care, struggling against the policies of insensitive and ignorant governments, but outsiders will see this as merely a disingenuous and self-serving ideology. Perhaps we should think uncomfortable thoughts rather than simplistic ones. First, the contractual relationship between general practice and the NHS inhibits investment rather than promotes it, leaving us under-equipped. Second, this results in a failure to modernise general practice fast enough to keep up with the expansion of medical knowledge and technology, in a rapidly changing society. Third, the gatekeeper function has all but collapsed in some places and in some clinical domains; at least a quarter of GP referrals to hospital chest clinics could be dealt with in general practice $^{3}$ (if it were more skilled and better organised), and $40-80 \%$ of ENT referrals may be similar. ${ }^{4}$

If these thoughts are right, the position is untenable, but I cannot see how GPs can escape from it by enhancing their communication skills or claiming some special 'biopsychosocial' understanding that on closer examination looks quite superficial. Roger Jones is right that tenacity, commitment, and imagination are needed to sustain good quality general practice; but without investment in skills and technology, practices will not assimilate current changes. A systematic approach to increasing skills demands time rather than money, and is perfectly possible to do within practices. Investment in technology is a tougher decision but, in my view, the question for practices is not: 'Can we afford to buy an ultrasound scanner?', it is: 'How can we not?'.

\section{Steven Iliffe}

Professor of Primary Care for Older People, University College London, Rowland Hill St, London NW3 2PF.

E-mail: s.iliffe@pcps.ucl.ac.uk

\section{REFERENCES}

1. Jones R. Dismantling general practice. Br J Gen Pract 2007; 57 544): 860-861.

2. Keeley D. The future of general practice: personal care or the polyclinic? BMJ 1991; 302(6791): 1514-1516.

3. Gilbert R, Franks G, Watkin S. The proportion of general practitioner referrals to a hospital respiratory medicine clinic suitable to be seen in a GPwSI respiratory clinic. Prim Care Respir J 2005; 14(6): 314-319.

4. Nocon A, Leese B. The role of UK general practitioners with pecial clinical interests: implications for policy and service delivery Br J Gen Pract 2004 : 54(498): 50-56.

\section{Dismantling general practice}

'Dismantling general practice' was a sobering paper, indeed. ${ }^{1}$ I note that Roger Jones' earliest reference is dated 1974.

This process was initiated long before this, with the instigation of merit awards for a proportion of consultants, the purchase and sale of goodwill in general practice being made illegal and case notes becoming the property of the Minister of Health - at the very outset of the NHS.

So what kind of jewel are we talking about? The fantasy of the jewel came much later - perhaps it would be charitable to suggest that Bevan was confused by carats and carrots? He certainly rejoiced in his successful use of the latter when devising merit awards, claiming publicly that he has ' ... stuffed their mouths with gold.' - his words, not mine. And he was greatly encouraged by the words of a distinguished physician who told him that the GP was '... the doctor who had fallen off the ladder of success.' To complement the carrot, of course, he used the stick on GPs in effectively confiscating their hard-earned (or dearly-borrowed) investment.

Added to this disgraceful employment of bribery and blackmail, by destroying the privacy of case notes he ensured the ultimate demise of the very core of topclass general practice - the trust underlying the precious doctor-patient relationship.

I do not very much care for having become a patient. But worse is having to pay more and more tax to fund this sorry dismantling.

\section{John K Paterson \\ Cambridge \\ E-mail: j.paterson275@btinternet.com}

\section{REFERENCE}

. Jones R. Dismantling general practice. Br I Gen Pract 2007; 57 (544): 860-861.

\section{Supporting self-care in general practice}

In their discussion of the complex issues around supporting self-care in general practice, Greaves and Campbell state that a prerequisite is '.. that the initiative has the full support of the healthcare team." We agree that this is a key to achieving optimal care. Our recent experience in the early stage of a community-based trial of home blood pressure monitoring highlights the importance of involving both patients and their GPs.

We are currently carrying out a randomised controlled trial in 360 patients who have had a stroke. The aim is to see if home blood pressure monitoring with nurse-led support is associated with lower systolic blood pressure after 1 year. Three foundation year two doctors helped with the initial planning of the trial and implementation of the pilot study.

Twenty baseline home visits were carried out with 10 patients randomised 